\title{
Metabolism of Proteins and Amino Acids in Critical Illness: From Physiological Alterations to Relevant Clinical Practice
}

\author{
Chih-Chieh Hsu' \\ Ci-Yuan Sun ${ }^{2}$ \\ Chun-Yi Tsai ${ }^{1}$ \\ Ming-Yang Chen' \\ Shang-Yu Wang $\mathbb{D}^{1,3}$ \\ Jun-Te Hsu ${ }^{1,3}$ \\ Chun-Nan Yeh ${ }^{1,3}$ \\ Ta-Sen Yeh ${ }^{1,3}$ \\ 'Division of General Surgery, Chang \\ Gung Memorial Hospital, Taoyuan, 333, \\ Taiwan; ${ }^{2}$ Division of Colon \& Rectal \\ Surgery, Chang Gung Memorial Hospital, \\ Taoyuan, 333, Taiwan; ${ }^{3}$ Chang Gung \\ University, Taoyuan, 333, Taiwan
}

\begin{abstract}
The clinical impact of nutrition therapy in critically ill patients has been known for years, and relevant guidelines regarding nutrition therapy have emphasized the importance of proteins. During critical illness, such as sepsis or the state following major surgery, major trauma, or major burn injury, patients suffer from a high degree of stress/inflammation, and during this time, metabolism deviates from homeostasis. The increased degradation of endogenous proteins in response to stress hormones is among the most important events in the acute phase of critical illness. Currently published evidence suggests that adequate protein supplementation might improve the clinical outcomes of critically ill patients. The role of sufficient protein supplementation may even surpass that of caloric supplementation. In this review, we focus on relevant physiological alterations in critical illness, the effects of critical illness on protein metabolism, nutrition therapy in clinical practice, and the function of specific amino acids.
\end{abstract}

Keywords: critical illness, protein, metabolism, amino acid

\section{Introduction}

Nutrition therapy has been recognized as a pivotal component of critical care medicine for years. Malnutrition appears to alter patient outcomes and is associated with a higher rate of complications, increased mortality, longer hospital length of stay (LOS) and increased hospital costs. ${ }^{1,2}$ According to the 2019 European Society for Clinical Nutrition and Metabolism (ESPEN) guidelines, all critically ill patients staying for more than 48 hours in the intensive care unit (ICU) should be considered at risk for malnutrition, and nutrition therapy should be administered to all patients staying in the ICU. ${ }^{3}$ Proteins are undoubtedly among the most important macronutrients in nutrition therapy. Current cumulative evidence indicates the importance of protein administration and its impact on the clinical outcomes of critically ill patients. ${ }^{4,5}$ The adequate delivery of proteins might have a higher impact than caloric delivery. ${ }^{4}$

Critical illness, such as major trauma or sepsis, is characterized by a high degree of stress/inflammation. Stress induces neuroendocrine changes, and inflammatoryrelated cytokine effects further modulate human metabolism. ${ }^{6,7}$ Normal metabolism is shifted to a hypercatabolic status, especially during the acute phase. ${ }^{8}$ The accelerated degradation of body reserves, including proteins, may cause malnutrition and organ dysfunction during the later stage under inappropriate management.
Correspondence: Shang-Yu Wang

Emaild0100106@cgu.edu.tw 
The increased degradation of endogenous proteins in response to stress hormones is among the most important events. ${ }^{8}$ Several currently published studies suggest that correctly timed adequate protein supplementation improves the clinical outcomes of critically ill patients. ${ }^{9,10}$

In this article, we review the neuroendocrine and inflammatory responses in critical illness and their effects on protein and amino acid metabolism. Then, we focus on the clinical practice of nutrition therapy and protein administration. In addition, the effects of several specific amino acids on immune modulation are elucidated.

\section{Physiological Impact of Critical Illness}

Critical illness resulting from sepsis, trauma, burns or major surgery shifts normal metabolism to a dynamic state to address different demands during different phases of the disease. Metabolic conditions can be divided into different stages. During the acute phase, the patient encounters the ebb phase, which includes the initial 24 to 48 hours, and the flow phase, which extends until 7 days. ${ }^{11}$ After the acute phase, some patients may enter the recovery stage, while other patients remain in a stage of prolonged critical illness. ${ }^{3}$ During the ebb phase, the metabolic status responds to tissue hypoperfusion and vasoconstriction and shifts to a status of decreased overall metabolism. ${ }^{12}$ The most prominent metabolic change during the ebb phase is glycogenolysis, which occurs in the liver in response to a catecholamine surge. ${ }^{13}$ After the ebb phase (ie, during the flow phase), the catabolic response increases, and the degradation of human stored components, including proteins, occurs. According to the current guidelines for nutrition therapy, we call the "flow phase" the "late period of the acute phase", which is when hypercatabolism occurs, and both the recovery stage and prolonged critical illness stage are considered the post-acute phase. ${ }^{3}$ In the following paragraphs, we discuss the metabolic changes in proteins and amino acids that occur during the late period of the acute phase and the post-acute phase. Regarding the post-acute phase, we mention metabolic changes in both patients in the recovery stage and those with prolonged critical illness.

\section{Late Period of the Acute Phase of Critical Illness}

Humans do not need proteins as a fuel but need proteins to increase their body cell mass during growth, recovery, or adaptation under steady-state conditions. ${ }^{14}$ However, proteins become the main energy substrate during the catabolic phase of critical illness. ${ }^{2}$ The human body does not have any "reserved protein storage"; all proteins in the body exist for structural or functional purposes. ${ }^{2}$ A rapid net catabolism of body proteins, which occurs particularly in skeletal muscle, has been demonstrated. ${ }^{15}$ Muscle loss is thought to be due to amino acid transport from the periphery to vital organs in the splanchnic area, especially the gut and liver, for gluconeogenesis, protein synthesis (acute phase proteins), and substrates for immune cells. ${ }^{16,17}$ Gamrin et al conducted a study investigating skeletal degradation. ${ }^{18}$ By obtaining muscle biopsies from 20 critically ill patients (APACHE II scores of 11 to 30 ) and 17 metabolically healthy patients, these authors demonstrated that the total free amino acids in skeletal muscle decreased by $59 \%$ and the skeletal muscle glutamine concentration decreased by $72 \%$ in critically ill patients. A recent study conducted by Puthucheary et al (MUSCLE study) further recognized an acute wasting of skeletal muscle that occurred early and rapidly during the first week of critical illness and was highly correlated with the disease severity. ${ }^{19}$ Puthucheary's findings revealed that patients with critical illness suffer from acute protein breakdown and a decrease in protein synthesis during the acute phase of critical illness, and a $15 \%$ decrease in the muscle amount occurs in patients with multiple organ failure. Then, Puthucheary et al extended their study to the relationship between bioenergetics changes and skeletal muscle wasting. ${ }^{20}$ Vastus lateralis muscle biopsies and serum samples (ICU admission days 1 and 7) were obtained from the same 63 intensive care patients in the MUSCLE study. Puthucheary's findings revealed a reduction in the mitochondrial betaoxidation enzyme concentrations and intramuscular ATP content and an increase in intramuscular tumor necrosis factor receptor 1 and IL-10 from days 1 to 7, indicating that a relationship exists between an impaired bioenergetic status and acute muscle wasting during early critical illness.

The nitrogen balance is another indicator of protein utilization. Sakurai et al demonstrated an increased consumption of proteins by observing the nitrogen balance. ${ }^{21}$ Each 6.25 grams of proteins contain 1 gram of nitrogen, and a negative nitrogen balance can be observed in patients with critical illness by observing the nitrogen balance or using a constant essential amino acid tracer infusion method. Using a radioisotope technique to label 
the essential amino acid leucine, Jackson et al demonstrated that both nonoxidative leucine disposal and leucine oxidation/metabolic clearance rates were increased in patients with critical illness. ${ }^{22}$ Jackson's study revealed that both an increase in the proteolysis and synthesis of acute phase proteins and an increase in protein turnover contribute to an increase in the metabolism of proteins.

In summary, the overall consumption of proteins is significant during critical illness. The net effect of multiple factors, including the sympathetic response, the neuroendocrine response, and inflammatory cytokines, contributes to this metabolic phenomenon (Figure 1). The consumption of proteins is significant during the acute phase of critical illness.

\section{Protein Metabolism During the Post-Acute Phase: Recovery vs Prolonged Critical Illness}

Patients who survive the acute phase of critical illness enter the post-acute phase, ie, either the recovery stage or prolonged critical illness. If the etiology of the critical illness is properly addressed and eliminated, the patient enters the recovery stage. Currently, over $70 \%$ of ICU patients recover within 1 week. ${ }^{23}$ When a patient enters the recovery stage, both the energy requirement and the protein requirement increase to replace the body mass lost during the acute phase. This phenomenon has been proven by Uehara et al immediately before this century by measuring energy expenditure and body composition. ${ }^{24}$ Anabolism is observed during this stage of critical disease.

If the etiology of critical illness cannot be solved, the patient enters a phase of prolonged critical illness. The physiological response during this stage greatly differs from that during the acute phase. In neuroendocrine aspects, a decrease in function is the major presentation. The major pathways of the neuroendocrine system involved in metabolism, including the growth hormone axis, pituitary-thyroid axis, pituitary-adrenocortical axis, are generally suppressed. ${ }^{23}$ Under the aforementioned effects, patients with prolonged critical illness suffer

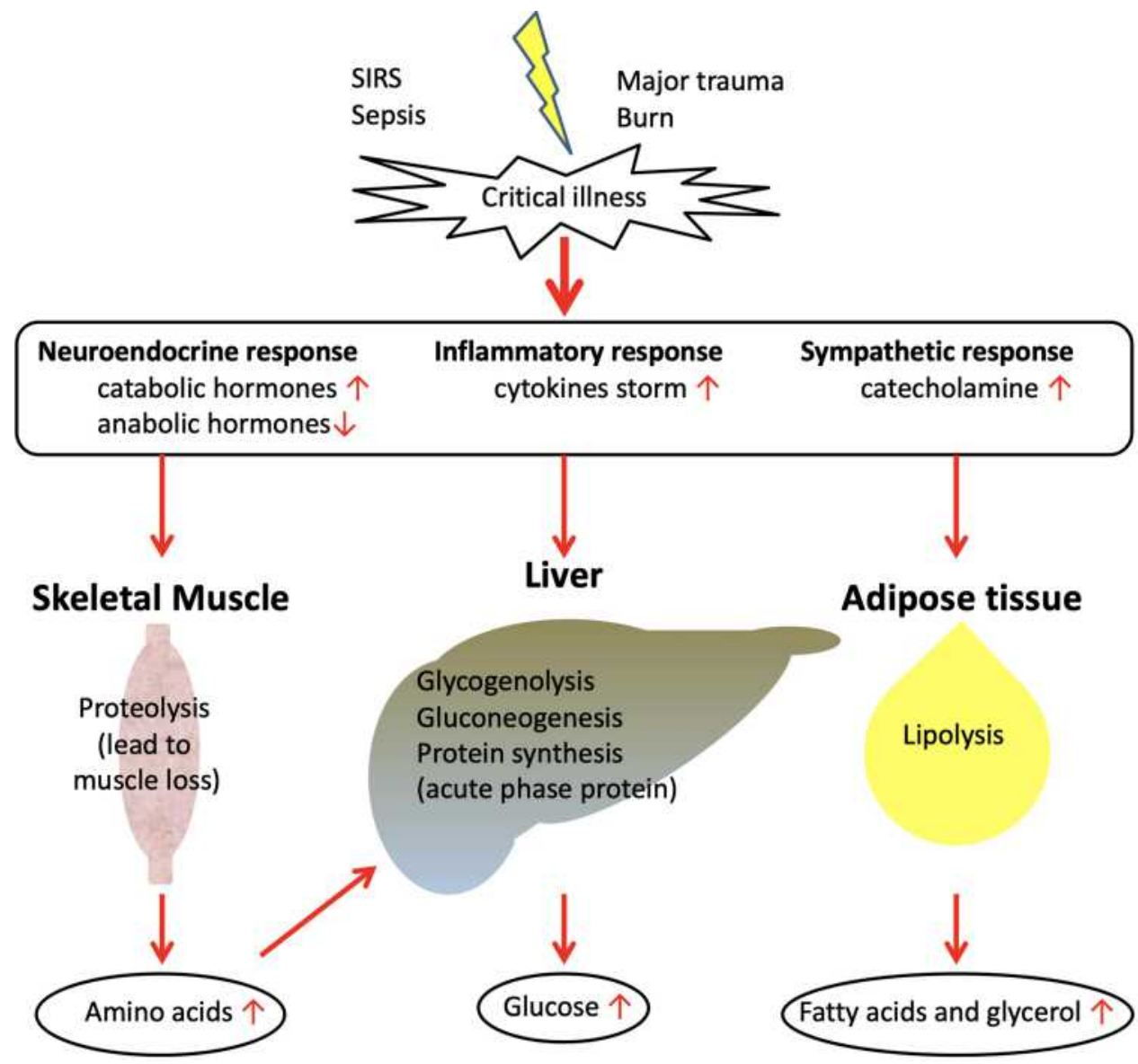

Figure I Metabolic response during the acute phase of critical illness: protein consumption. 
from catabolism rather than anabolism and the restoration of body structure and lost body mass. ${ }^{3}$ The cytokine immune response affects metabolism, and its effect cannot be overemphasized during the acute phase; its functional alteration in prolonged critical illness also has an impact. ${ }^{6,15}$ While the initial cytokine storm characterizes the acute phase of critical illness, the immune status usually returns to homeostasis during the recovery stage. However, patients suffer from prolonged critical illness, and their immune system enters a specific condition, ie, persistent inflammation/immunosuppression and catabolism syndrome (PICS). ${ }^{25}$ PICS is characterized by markedly increased C-reactive protein concentrations, neutrophilia, and the release of immature myeloid cells. ${ }^{26}$ Rosenthal et al demonstrated that patients with PICS presented with persistent inflammatory conditions (elevated IL-6 and IL- 8 levels) and immunosuppression (decreased lymphocyte count). ${ }^{27}$ The restoration of metabolic homeostasis failed, and catabolism persisted as demonstrated by relevant biomarkers, including higher glucagon-like peptide and a higher 1,3-methylhistidine/creatinine ratio. In addition, the persistent synthesis of acute phase proteins, such as persistently elevated C-reactive protein, was also noted. In summary, patients with PICS suffer from persistent low-grade inflammation that drives catabolism and blocks anabolism. ${ }^{28}$

\section{Protein Absorption in Critical Illness}

To maintain body proteins, it is important to provide adequate nutritional intake of proteins. However, whether the human body can absorb and metabolize nutritional proteins during critical illness remains uncertain. Gastrointestinal failure was observed in $10.4 \%$ of critically ill adults in a retrospective study. ${ }^{29}$ Gastrointestinal symptoms/failure is also associated with an increased risk of mortality. ${ }^{30}$ Gastrointestinal dysfunction indicates functional impairment of the alimentary tract that may include disturbances in motility or absorption, breaches in the mucosal integrity, changes in the microbiome, increased intraabdominal pressure, impaired mesenteric perfusion and an impaired local immune response in the bowel. ${ }^{31}$ Therefore, the digestion of proteins and absorption of amino acids could be affected under the circumstances of critical disease and lead to protein malabsorption.

Compared with glucose or lipids, evidence regarding protein digestion and absorption during critical illness is scarce. Liebau et al established a method for quantifying the effect of enteral protein feeding in critically ill patients receiving early enteral nutrition. ${ }^{32}$ These authors reported that the uptake of labeled ${ }^{13} \mathrm{C}$-phenylalanine from diet could be detected in plasma after nasogastric feeding in most adult elderly critically ill patients. However, the isotope-labeled amino acid plasma concentration was much lower than that in the healthy volunteers. This result showed that critically ill patients could digest and absorb proteins from enteral feeding but might be affected by impaired digestion or absorption or greater splanchnic extraction.

Splanchnic extraction represents the fraction of ingested amino acids taken up by the splanchnic organs (gut or liver) that is not available systemically, eg, not available to muscles. ${ }^{33,34}$ This phenomenon is greater among the elderly and presents substantial variability during critical illness. ${ }^{33,35}$ This variation is correlated with the protein amount provided in enteral nutrition. It seems that the lower the protein intake, the higher the fractional splanchnic extraction presented. ${ }^{36,37}$ These studies suggest that splanchnic organs extract the amino acids required for regional metabolism during feeding and then release the remainder to the central circulation. Another small sample size randomized trial also reported that a full dose of enteral nutrition delivered more amino acids to the central circulation than a half dose of enteral nutrition and led to a more positive protein balance in adult critically ill patients. ${ }^{36}$ In summary, since the digestion of proteins and absorption of amino acids are affected in critical illness, our goal is to supply adequate proteins to these patients to deliver more amino acids to the systemic circulation.

\section{Protein Deficiency and Clinical Outcomes \\ Protein Deficiency}

In ICU patients, the nutritional status should be assessed after admission. Idrissi et al reported that $42.9 \%$ of patients had low plasma levels of prealbumin, $73.6 \%$ of patients had low plasma albumin and $99 \%$ of patients had low plasma transferrin upon admission to the ICU. ${ }^{38}$ However, laboratory data alone may not be reliable for nutrition assessments under the circumstances of a critical illness, and multiple monitoring, including laboratory and other clinical aspects, is necessary. ${ }^{39}$ Since net protein consumption results in muscle wasting, the change in the body composition is also an important observation related to the nutrition status, ${ }^{40}$ especially in the case of a protein 
deficiency. The composition of the human body is divided into lean mass, containing water plus all proteins, and fat mass, containing mainly fat-energy stores. A change in the body composition is a characteristic of patients with critical illness, and this change is due to protein breakdown. The rapid net catabolism of body proteins, which occurs particularly in skeletal muscle, ${ }^{15}$ renders muscle loss an indicator of protein deficiency in critically ill patients. A loss of more than $10 \%$ of lean body mass decreases immunity and increases the risk of infection, while a loss of more than $20 \%$ of lean body mass decreases wound healing and increases muscle weakness. ${ }^{41}$ Furthermore, notably, with a loss of $30 \%$ or more of lean body mass, the wound healing rate is decreased until lean mass is restored. ${ }^{42}$ In a study of measurements of muscle wasting during critical illness, significant reductions in the rectus femoris cross-sectional area were observed on day 10 $(-17.7 \%$ [95\% CI, $-20.9 \%$ to $-4.8 \%], \mathrm{p}<0.001) .{ }^{19}$ Therefore, the loss of muscle is a characteristic phenomenon of protein deficiency and a predictor of clinical outcomes. $^{43-47}$

\section{Short-Term Outcomes}

In critically ill patients, malnutrition and protein deficiency are important issues because they are associated with increased morbidity, mortality, LOS, use of healthcare resources and costs. ${ }^{48}$ Protein-energy malnutrition also causes impaired wound healing and the development of chronic wounds and infections.

The nutritional status of critically ill patients is a significant predictor of survival. According to a cohort study involving 6518 ICU patients, the nonspecific malnutrition 30-day mortality odds ratio (OR) was 1.17 (95\% confidence interval [CI], 1.01-1.37), and protein malnutrition increased the 30-day mortality with an OR of 2.10 (95\% CI, 1.70-2.59). ${ }^{49}$ A prospective observational cohort study involving 113 ICU patients also reported that the low-protein/amino-acid provision group was associated with a higher 28-day mortality than the high-protein /amino-acid provision group. ${ }^{50}$ Elke et al studied 2270 critically ill patients with a diagnosis of sepsis/pneumonia who were admitted to the ICU for $\geq 3$ days, mechanically ventilated within 48 hours of ICU admission and only received enteral nutrition. ${ }^{51}$ The results showed that the provision of an additional 30 grams of protein per day decreased the 60-day mortality and days of ventilator use. Another multicenter international study conducted by Nicolo et al reported a cohort of 1584 patients who stayed in the ICU $\geqq 12$ days. $^{4}$ The authors reported that the time to discharge alive (TDA) was shorter in patients who were prescribed adequate proteins (intake $\geq 80 \%$ goal amount) compared with those patients who were not (hazard ratio [HR], 1.25; 95\% CI, 1.04-1.49). In summary, protein deficiency in critically ill patients might be associated with a higher mortality rate and a worse prognosis and restoring the protein deficiency may improve the clinical outcomes.

\section{Long-Term Outcomes}

In addition to the increased short-term mortality rate, malnutrition and protein deficiency also have a negative impact on long-term survival and post-discharge outcomes. Mogensen et al reported an observational cohort of 23,575 patients who received critical care and then survived hospitalization. ${ }^{52}$ Mogensen's study revealed that the 90-day post-discharge mortality in patients at risk of malnutrition, nonspecific malnutrition, and protein-energy malnutrition fully adjusted relative to patients without malnutrition was $1.77,2.51$, and 3.72 , respectively. Furthermore, the ORs of 365-day postdischarge mortality in patients at risk for malnutrition, nonspecific malnutrition, and protein-energy malnutrition compared with that in patients without malnutrition was $1.14,1.70$, and 3.75 , respectively. In addition, the ORs of 30-day re-admission in patients at risk for malnutrition, nonspecific malnutrition, and protein-energy malnutrition was $1.08,1.20$, and 1.67 , respectively, compared with that of patients without malnutrition. Therefore, the overall clinical impact of protein deficiency is negative according to current evidence. Furthermore, malnutrition also has an influence in the social-economic aspect. For example, the British Association for Parenteral and Enteral Nutrition (BAPEN 2005) described that malnutrition costs the UK more than $£ 7.3$ billion per annum; $£ 3.8$ billion was spent on treating malnourished patients in the hospital, and £2.6 billion were spent on long-term care facilities. ${ }^{48}$

In summary, protein deficiency in patients with critical illness results from both excessive breakdown during the acute phase and inadequate protein provision. The negative impact of protein deficiency is extensive. Clinical management should attempt to reverse this condition after the initial acute phase. Therefore, nutrition therapy interventions are an important management tool used to improve clinical outcomes. 


\section{Protein Delivery in Critically III Patients}

\section{Timing and Amount of Protein Administration: Acute Phase}

The importance of protein supplementation in critically ill patients is currently well known, but how to deliver sufficient protein to ICU patients is still debatable In general, enteral nutrition $(\mathrm{EN})$ is considered superior to parenteral nutrition (PN), and EN should be initiated early (within 48 hours) in critically ill adult patients. ${ }^{3,53}$ Calorie/protein targets are determined to gradually achieve more than $70 \%$ of the resting energy expenditure (REE) but not $100 \%$ during the acute phase of critical illness. ${ }^{3}$

During the late period of the acute phase (ie, the flow phase), full EN or PN should be gradually achieved within three to seven days. The protein targets should gradually reach $1.3 \mathrm{~g} / \mathrm{kg}$ or 1.2 to $2.0 \mathrm{~g} / \mathrm{kg}$ protein per day, which is recommended for critically ill patients in the current guidelines (Table 1). ${ }^{3,54-56}$ Over the past several years, some experts have suggested that delivering more proteins is better for patients with critical illness and that even up to $2.0-2.5 \mathrm{~g} / \mathrm{kg} /$ day is safe and optimum. ${ }^{57,58}$ However, some studies, including several randomized controlled trials (RCTs), revealed that a higher protein formula has no impact on mortality in critically ill patients. Doig et al compared intravenous high-amino-acid therapy $(2.0 \mathrm{~g} / \mathrm{kg} /$ day) to standard nutrition care and reported no difference in mortality. ${ }^{59}$ A higher protein formula also had no effect on the ICU LOS, hospital LOS or duration of mechanical ventilation in critically ill patients. ${ }^{60}$ Thiessen et al explained that this phenomenon may be caused by the increasing amino acid levels during critical illness stimulating glucagon and resulting in more hepatic amino acid breakdown and ureagenesis. ${ }^{16}$ In conclusion, energy and protein delivery to critically ill patients should be established in a stepwise method to achieve the target (80$100 \%$ energy expenditure and $1.3 \mathrm{~g} / \mathrm{kg} /$ day protein) after day 3 in the acute phase to avoid overfeeding.

\section{Amino Acid Provision in Supplemental PN}

If a patient cannot tolerate an oral diet or EN or an oral diet or EN is contraindicated in a patient, the current consensus suggests that PN should be implemented within three to seven days. Parenteral amino acid therapy should be considered at this time. Ferrie et al compared PN solutions containing amino acids at $1.2 \mathrm{~g} / \mathrm{kg} /$ day to those containing amino acids at $0.8 \mathrm{~g} / \mathrm{kg} /$ day and reported no effect on mortality, ICU and hospital LOS or mechanical ventilation duration in critically ill patients. However, this study revealed better handgrip strength on study day 7 , a lower fatigue

Table I Protein Delivery Recommendations According to the Current Practice Guidelines

\begin{tabular}{|c|c|c|c|}
\hline & $\begin{array}{l}\text { ESPEN Guideline } \\
(2019)^{3}\end{array}$ & ASPEN Guideline $(2016)^{56}$ & Canadian Guideline $(2015,2021)^{54,84}$ \\
\hline $\begin{array}{l}\text { Daily protein } \\
\text { administration }\end{array}$ & $\begin{array}{l}1.3 \mathrm{~g} / \mathrm{kg} \text { protein equivalents } \\
\text { per day. }\end{array}$ & $1.2-2.0 \mathrm{~g} / \mathrm{kg}$ actual body weight per day. & Insufficient data to make a recommendation. \\
\hline $\begin{array}{l}\text { Branched Chain } \\
\text { Amino Acids } \\
\text { (BCAAs) }\end{array}$ & NA & $\begin{array}{l}\text { No evidence of benefit for patients with hepatic } \\
\text { encephalopathy. Guideline suggested standard } \\
\text { enteral formulations to be used in ICU patients } \\
\text { with acute and chronic liver disease. }\end{array}$ & $\begin{array}{l}\text { BCAA was associated with a trend towards } \\
\text { a reduction in mortality of critical ill patients, } \\
\text { but insufficient data to make } \\
\text { a recommendation. }\end{array}$ \\
\hline Arginine & NA & $\begin{array}{l}\text { Immune-modulating enteral formulations } \\
\text { (including arginine and glutamine) should not be } \\
\text { used routinely in the medical ICU; reserved for } \\
\text { patients with trauma and perioperative patients } \\
\text { in the surgical ICU. }\end{array}$ & $\begin{array}{l}\text { Diets supplemented with arginine used for } \\
\text { critically ill patients is not recommended. }\end{array}$ \\
\hline Glutamine (EN) & $\begin{array}{l}\text { Suggested for trauma and } \\
\text { burn patients but should } \\
\text { not be used in other ICU } \\
\text { patients. }\end{array}$ & Should not be added to an EN regimen. & $\begin{array}{l}\text { Not recommended for use in critically ill } \\
\text { patients. However, may benefit patients with } \\
\text { burn or trauma. }\end{array}$ \\
\hline Glutamine (PN) & Should not be used. & Should not be used. & Should not be used. \\
\hline
\end{tabular}

Abbreviations: ESPEN, European Society for Clinical Nutrition and Metabolism; ASPEN, American Society for Parenteral and Enteral Nutrition; EN, enteral nutrition; PN, parenteral nutrition; NA, not available; ICU, intensive care unit. 
score and greater forearm muscle thickness on ultrasound. ${ }^{5}$ Parenteral amino acid provision can be an alternative to enteral formula, and the recommended dosage is similar.

\section{Timing and Amount of Protein Administration: Post-Acute Phase}

As mentioned in the section regarding the recovery stage of the post-acute phase, both energy requirements and protein requirements increase to replace the body mass lost during the acute phase. During this post-acute phase, activity and exercise increase. Therefore, the target calorie intake might increase to $125-150 \%$ of the predicted values, and the protein intake goal might increase to $1.5-2.5 \mathrm{~g} / \mathrm{kg} /$ day. ${ }^{10,61}$ During this time, patients are often discharged from the ICU and start oral intake. Therefore, clinicians should monitor the patient's oral intake amount to avoid insufficient protein intake. Ensuring that the feeding tube is not removed too early or providing oral nutrition supplemental products might resolve these problems. ${ }^{61}$ However, if the etiology of the critical illness cannot be resolved, the patient enters a phase of prolonged critical illness, and PICS might develop. As mentioned above, patients with PICS suffer from prolonged low-grade inflammation and catabolism with a loss of lean body mass. Nutritional support in these patients is similar to that in patients with sarcopenia or cancer cachexia, and the provision of $1.5-2.0 \mathrm{~g} / \mathrm{kg} / \mathrm{day}$ protein might be appropriate. ${ }^{28}$ A summary of the protein delivery in each specific phase is provided in Figure 2.

\section{Special Considerations of Amino Acids in Critical Care Branched-Chain Amino Acids}

A branched-chain amino acid (BCAA) is an amino acid that has an aliphatic side-chain with a branch. The three BCAAs are valine, leucine and isoleucine. All three BCAAs are essential amino acids for humans. The use of BCAAs in the treatment of hepatic failure and hepatic encephalopathy is based on enhanced detoxification of ammonia in skeletal muscle and the promotion of liver regeneration. ${ }^{62}$ According to some studies, BCAA supplementation appears to be associated with the prevention of progressive hepatic failure and a decreased frequency of complications of cirrhosis. ${ }^{63,64}$ However, BCAA supplementation may lead to enhanced ammonia production from glutamine breakdown in the gut and kidneys and, thus, has adverse effects on hepatic encephalopathy. ${ }^{65}$ Due to controversial evidence, the American Society for Parenteral and Enteral Nutrition (ASPEN) guidelines suggest that standard enteral formulations (not BCAA formulas) may be used in ICU patients with acute and chronic liver disease. ${ }^{56}$ In trauma patients without liver disease, a previous study also

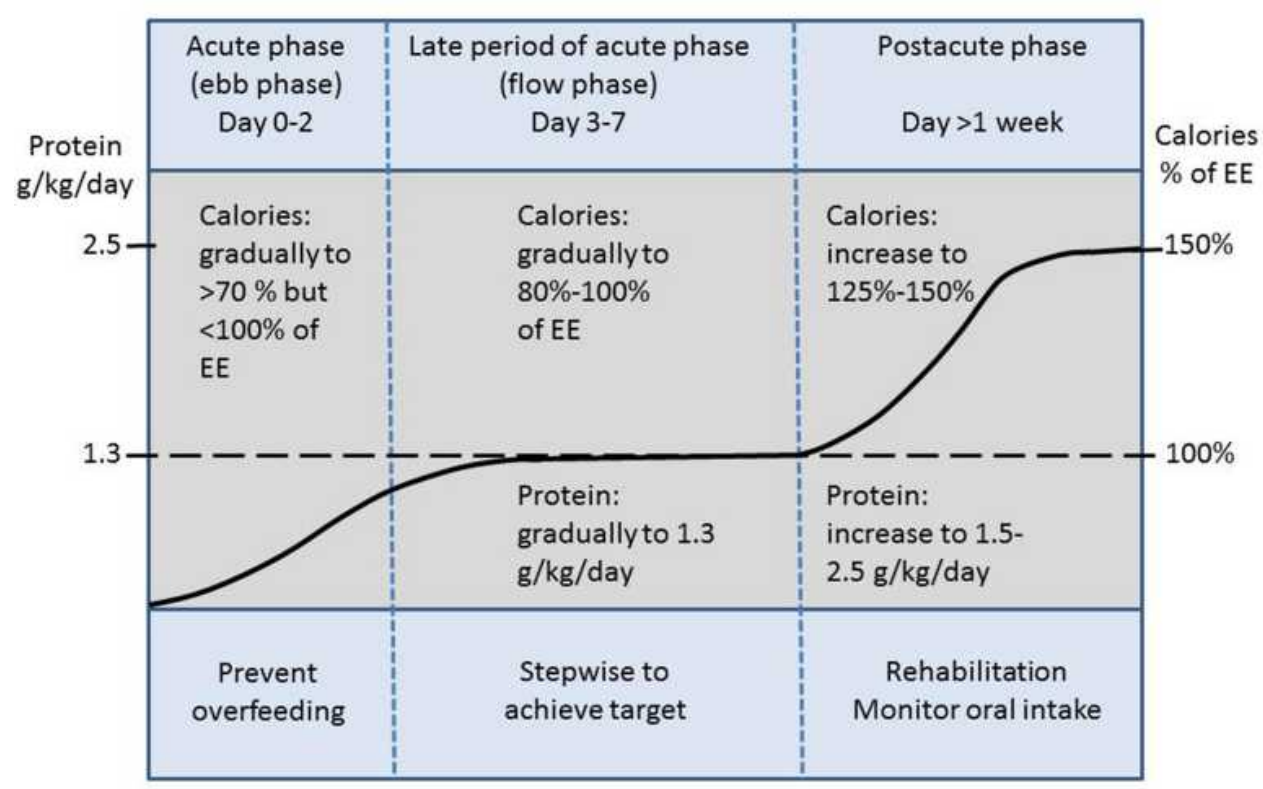

Figure 2 Protein delivery recommendations in critical illness. Adapted from. Figure I in Zanten et al Critical Care (2019) 23:368: Nutrition therapy and critical illness: Practical guidance for the ICU, post-ICU, and long-term convalescence phases. ${ }^{61}$

Abbreviation: EE, energy expenditure. 
reported no effect on mortality or the LOS in the ICU when a BCAA-enriched (45\%) parenteral solution was added to standard EN. ${ }^{66}$

\section{Arginine}

Arginine is classified as a nonessential amino acid in healthy individuals. However, arginine can become a conditionally essential amino acid during metabolic or traumatic stress because the endogenous arginine supply is inadequate to meet physiological demands. ${ }^{67}$ Arginine depletion during critical illness may have several important effects, including reduced NO production, poor wound healing, impaired microcirculatory blood flow, immunosuppression (T-cell dysfunction), and impaired muscle function. ${ }^{67,68}$ However, evidence of a benefit of arginine administration in ICU patients is still lacking. ${ }^{69}$ Tadié et al showed that early enteral L-arginine administration does not reverse immunosuppression or inflammation in medical ICU (MICU) patients. ${ }^{70}$ Luiking et al also reported no effect on global hemodynamics, organ function parameters or protein metabolism by L-arginine infusion in severe sepsis patients. ${ }^{71}$ However, a previous study reported that using an arginine-supplemented diet in perioperative patients reduced infection and the hospital LOS but had no significant effect on mortality. ${ }^{72}$ Therefore, the ESPEN guidelines for nutrition in critical illness had no recommendations related to arginine use. The 2016 Society of Critical Care Medicine (SCCM)/ASPEN nutrition therapy guidelines also suggest that immune-modulating enteral formulations (including arginine and glutamine) should not be used routinely in the MICU and that these formulations should be reserved for patients with trauma and perioperative patients in the surgical ICU (SICU). ${ }^{56}$

\section{Glutamine}

Glutamine is among the most abundant amino acids and is classified as a nonessential amino acid in the human body. However, glutamine may become a conditionally essential amino acid during stress. Glutamine is an important oxidative fuel for rapidly proliferating cells, including those in the gastrointestinal tract and immune system, and mainly serves as a precursor in the synthesis of other amino acids and glucose for energy. ${ }^{68}$ In addition, glutamine seems to be a potent enhancer of stress-induced heat shock protein expression, which can decrease cell death and organ injuries in several models of cellular stress. ${ }^{73}$

Numerous studies investigating the effects of glutamine have been published over the past years. Two major meta-analyses illustrated the positive effect of glutamine before 2014. Bollhalder et al analyzed forty randomized clinical trials and reported no significant reduction in short-term mortality but found reduced infection and hospital LOS with parenteral glutamine supplementation in severely ill patients. ${ }^{74}$ Wischmeyer et al also analyzed 26 RCTs and reported that parenteral glutamine supplementation was associated with a significant reduction in hospital mortality and the hospital LOS. ${ }^{75}$ However, this beneficial effect was only observed in single-center studies and not in multicenter studies during the subgroup analysis.

Since 2013, several strong studies investigating the negative influence of glutamine have been published. One multicountry, multicentered large RCT (1223 critically ill patients in 40 ICUs who received supplements of glutamine, antioxidants, both, or placebo), the REDOXS study, reported that the early provision of glutamine did not improve survival and was associated with an increase in mortality among critically ill patients with multiorgan failure. ${ }^{76,77}$ Another MetaPlus study compared high-protein EN enriched with immune-modulating nutrients (IMHP, including glutamine, omega-3 fatty acids, and antioxidants) to standard high-protein EN (HP) in mechanically ventilated critically ill patients. The results showed that the IMHP group did not show improvements in infectious complications but had a higher 6-month mortality rate than the medical subgroup. ${ }^{78}$ A recent metaanalysis also reported that enteral glutamine provision resulted in no significant difference in mortality or the length of hospitalization. ${ }^{79}$

However, some evidence has proven that glutamine has benefits in subgroups of critical patients. Glutaminesupplemented EN could be associated with a reduction in hospital mortality and bacteremia in burn patients and a reduction in infectious complications in multipletrauma patients. ${ }^{80,81}$ Finally, Stehle et al published a metaanalysis (15 RCTs involving 842 patients) of studies that enrolled only hemodynamically stable patients without liver or renal failure. The conclusion showed that parenteral glutamine dipeptide supplementation significantly reduced infectious complications, the ICU LOS, the hospital LOS, and the mechanical ventilation duration and lowered the hospital mortality rate by $45 \%$ but had no effect on ICU mortality. ${ }^{82}$ In conclusion, supplemental glutamine might be used cautiously in surgical patients with burns or multiple traumas and stable medical patients. ${ }^{83}$ The current published nutritional guidelines 
also have conservative recommendations for glutamine use in critical patients (Table 1).

\section{Conclusion}

Amino acid and protein metabolism are altered when the human body faces stress, such as sepsis, trauma or major surgery. Under such a clinical setting, protein-energy malnutrition results in an increased mortality rate and several other negative influences on the hospital LOS and longterm outcomes. Understanding these changes and issues could help clinicians provide adequate and appropriate nutrition therapy to critically ill patients, especially during the late acute phase and post-acute phase. While several specific amino acids, including arginine and glutamine, may have immunomodulatory effects, the current level of evidence is still weak. During clinical practice for patients with critical illness, giving protein supplementation to the right patient at the right time in an adequate amount may optimize the overall clinical outcome.

\section{References}

1. Barker LA, Gout BS, Crowe TC. Hospital malnutrition: prevalence, identification and impact on patients and the healthcare system. Int J Environ Res Public Health. 2011;8(2):514-527. doi:10.3390/ ijerph8020514.

2. Sharma K, Mogensen KM, Robinson MK. Pathophysiology of critical illness and role of nutrition. Nutr Clin Pract. 2019;34(1):12-22. doi:10.1002/ncp.10232.

3. Singer P, Blaser AR, Berger MM, et al. ESPEN guideline on clinical nutrition in the intensive care unit. Clin Nutr. 2019;38:48-79. doi:10.1016/j.clnu.2018.08.037.

4. Nicolo M, Heyland DK, Chittams JESSE, Sammarco T, Compher C. Clinical outcomes related to protein delivery in a critically ill population: a multicenter, multinational observation Study. J Parenter Enter Nutr. 2016;40(1):45-51. doi:10.1177/0148607115583675.

5. Ferrie S, Allman-Farinelli M, Daley M, Smith K. Protein requirements in the critically Ill: a randomized controlled trial using parenteral nutrition. J Parenter Enter Nutr. 2016;40(6):795-805. doi: $10.1177 / 0148607115618449$.

6. Souba WW. Cytokine control of nutrition and metabolism during critical illness. Curr Probl Surg. 1994;31(7):587-643. doi:10.1016/ 0011-3840(94)90047-7.

7. DiGirolamo FG, Situlin R, Biolo G. What factors influence protein synthesis and degradation in critical illness? Curr Opin Clin Nutr Metab Care. 2017;20(2):124-130. doi:10.1097/MCO.000000000000 0347.

8. Wischmeyer PE. Nutrition therapy in sepsis. Crit Care Clin. 2018;34 (1):107-125. doi:10.1016/j.ccc.2017.08.008.

9. Alberda C, Gramlich L, Jones N, et al. The relationship between nutritional intake and clinical outcomes in critically ill patients: results of an international multicenter observational study. Intensive Care Med. 2009;35(10):1728-1737. doi:10.1007/s00134-009-1567-4.

10. Wischmeyer PE. Tailoring nutrition therapy to illness and recovery. Crit Care. 2017;21(S3). doi:10.1186/s13054-017-1906-8.

11. Ryan NT. Metabolic adaptations for energy production during trauma and sepsis. Surg Clin North Am. 1976;56(5):1073-1090. doi:10.1016/ S0039-6109(16)41032-7.
12. Mizock BA. Metabolic derangements in sepsis and septic shock. Crit Care Clin. 2000;16(2):319-336. doi:10.1016/S0749-0704(05)70112-3.

13. Barton RN. Neuroendocrine mobilization of body fuels after injury. Br Med Bull. 1985;41(3):218-225. doi:10.1093/oxfordjournals.bmb. a072054.

14. Hoffer LJ. Human protein and amino acid requirements. J Parenter Enter Nutr. 2014;40(4):460-474. doi:10.1177/0148607115624084.

15. Fischer JE, Hasselgren PO. Cytokines and glucocorticoids in the regulation of the "hepato-skeletal muscle axis" in sepsis. Am J Surg. 1991;161(2):266-271. doi:10.1016/0002-9610(91)91143-7.

16. Thiessen SE, Gunst J, Van DenBerghe G. Role of glucagon in protein catabolism. Curr Opin Crit Care. 2018;24(4):228-234. doi:10.1097/ MCC.0000000000000509.

17. Fischer CP, Bode BP, Abcouwer SF, Lukaszewicz GC, Souba WW. Hepatic uptake of glutamine and other amino acids during infection and inflammation. Shock. 1995;3(5):315-322.

18. Gamrin L, Essén P, Forsberg AM, Hultman E, Wernerman J. A descriptive study of skeletal muscle metabolism in critically ill patients: free amino acids, energy-rich phosphates, protein, nucleic acids, fat, water, and electrolytes. Crit Care Med. 1996;24 (4):575-583. doi:10.1097/00003246-199604000-00005.

19. Puthucheary ZA, Rawal J, McPhail M, et al. Acute skeletal muscle wasting in critical illness. JAMA. 2013;310:1591-1600. doi:10.1001/ jama.2013.278481.

20. Puthucheary ZA, Astin R, McPhail MJW, et al. Metabolic phenotype of skeletal muscle in early critical illness. Thorax. 2018;73 (10):926-935. doi:10.1136/thoraxjnl-2017-211073.

21. Sakurai Y. Protein metabolism in critical illness: methodologies and their problems underlying in kinetic studies using isotope tracers in vivo. Keio J Med. 1999;48(2):69-78. doi:10.2302/kjm.48.69.

22. Jackson NC, Carroll PV, Russell-Jones DL, Sonksen PH, Treacher DF, Umpleby AM. The metabolic consequences of critical illness: acute effects on glutamine and protein metabolism. $\mathrm{Am}$ J Physiol Endocrinol Metab. 1999;276(1):E163-E170. doi:10.1152/ ajpendo.1999.276.1.e163.

23. Van DenBerghe G. On the neuroendocrinopathy of critical illness: perspectives for feeding and novel treatments. Am J Respir Crit Care Med. 2016;194(11):1337-1348. doi:10.1164/rccm.201607-1516CI.

24. Uehara M, Plank LD, Hill GL. Components of energy expenditure in patients with severe sepsis and major trauma: a basis for clinical care. Crit Care Med. 1999;27(7):1295-1302. doi:10.1097/00003246199907000-00015.

25. Gentile LF, Cuenca AG, Efron PA, et al. Persistent inflammation and immunosuppression: a common syndrome and new horizon for surgical intensive care. J Trauma Acute Care Surg. 2012;72 (6):1491-1501. doi:10.1097/TA.0b013e318256e000

26. Hotchkiss RS, Moldawer LL, Opal SM, Reinhart K, Turnbull IR, Vincent JL. Sepsis and septic shock. Nat Rev Dis Prim. 2; 2016. doi:10.1038/nrdp.2016.45.

27. Rosenthal MD, Bala T, Wang Z, Loftus T, Moore F. Chronic critical illness patients fail to respond to current evidence-based intensive care nutrition secondarily to persistent inflammation, immunosuppression, and catabolic syndrome. J Parenter Enter Nutr. 2020;44 (7):1237-1249. doi:10.1002/jpen.1794.

28. Moore FA, Phillips SM, McClain CJ, Patel JJ, Martindale RG. Nutrition support for persistent inflammation, immunosuppression, and catabolism syndrome. Nutr Clin Pract. 2017;32(1_suppl):121S127S. doi: $10.1177 / 0884533616687502$.

29. Padar M, Starkopf J, Uusvel G, Reintam blaser A. Gastrointestinal failure affects outcome of intensive care. $J$ Crit Care. 2019;52:103-108. doi:10.1016/j.jcrc.2019.04.001.

30. Reintam Blaser A, Poeze M, Malbrain MLNG, Björck M, Oudemans-van Straaten HM, Starkopf J. Gastrointestinal symptoms during the first week of intensive care are associated with poor outcome: a prospective multicentre study. Intensive Care Med. 2013;39 (5):899-909. doi:10.1007/s00134-013-2831-1. 
31. Reintam Blaser A, Preiser JC, Fruhwald S, et al. Gastrointestinal dysfunction in the critically ill: a systematic scoping review and research agenda proposed by the Section of metabolism, endocrinology and nutrition of the european society of intensive care medicine. Crit Care. 2020;24(1):224. doi:10.1186/s13054-02002889-4.

32. Liebau F, Wernerman J, VanLoon LJC, Rooyackers O. Effect of initiating enteral protein feeding on whole-body protein turnover in critically ill patients. Am J Clin Nutr. 2015;101(3):549-557. doi:10. 3945/ajen.114.091934.

33. Boirie Y, Gachon P, Beaufrère B. Splanchnic and whole-body leucine kinetics in young and elderly men. Am J Clin Nutr. 1997;65 (2):489-495. doi:10.1093/ajen/65.2.489.

34. Liebau F, Sundström M, vanLoon LJC, Wernerman J, Rooyackers O. Short-term amino acid infusion improves protein balance in critically ill patients. Crit Care. 2015;19(1):1-10. doi:10.1186/s13054-0150844-6.

35. Weijs PJM, Cynober L, DeLegge M, Kreymann G, Wernerman J, Wolfe RR. Proteins and amino acids are fundamental to optimal nutrition support in critically ill patients. Crit Care. 2014;18 (6):1-13. doi:10.1186/s13054-014-0591-0.

36. Rehal MS, Liebau F, Wernerman J, Rooyackers O. Whole-body protein kinetics in critically ill patients during 50 or $100 \%$ energy provision by enteral nutrition: a randomized cross-over study. PLoS One. 2020;15:1-14. doi:10.1371/journal.pone.0240045.

37. Liebau F, Deane AM, Rooyackers O. Protein absorption and kinetics in critical illness. Curr Opin Clin Nutr Metab Care. 2021;24 (1):71-78. doi:10.1097/MCO.0000000000000707.

38. Hicham Bouharras El Idrissi, López JM, et al. Original/Intensivos Imbalances in protein metabolism in critical care patient with systemic inflammatory response syndrome at admission in intensive care unit. Nutricion hospitalaria. 2015;32(6):2848-2854. doi:10.3305/ nh.2015.32.6.9827.

39. Berger MM, Reintam-Blaser A, Calder PC, et al. Monitoring nutrition in the ICU. Clin Nutr. 2019;38(2):584-593. doi:10.1016/j. clnu.2018.07.009.

40. Barreto EF, Kanderi T, DiCecco SR, et al. Sarcopenia index is a simple objective screening tool for malnutrition in the critically ill. JPEN J Parenter Enteral Nutr. 2019;43(6):780-788. doi:10.1002/ jpen.1492.

41. Argilés JM, Campos N, Lopez-Pedrosa JM, Rueda R, RodriguezMañas L. Skeletal muscle regulates metabolism via interorgan crosstalk: roles in health and disease. $J$ Am Med Dir Assoc. 2016;17 (9):789-796. doi:10.1016/j.jamda.2016.04.019.

42. Demling RH. Nutrition, anabolism, and the wound healing process: an overview. Eplasty. 2009;9:e9.

43. Ji Y, Cheng B, Xu Z, et al. Impact of sarcopenic obesity on 30-day mortality in critically ill patients with intra-abdominal sepsis. J Crit Care. 2018;46:50-54. doi:10.1016/j.jcrc.2018.03.019.

44. Zhi J, Shan Q, Liang L, Liu H, Huang H. Low skeletal muscle area as a prognostic marker for chronic obstructive pulmonary disease in elderly patients admitted to ICU. Sci Rep. 2019;9(1):19117. doi:10.1038/s41598-019-55737-z.

45. Seo D-W, Kim KW, Sohn CH, et al. Progressive loss of muscle mass could be an adverse prognostic factor of 28-day mortality in septic shock patients. Sci Rep. 2019;9(1):16471. doi:10.1038/s41598-01952819-w.

46. Loosen SH, Schulze-Hagen M, Püngel T, et al. Skeletal muscle composition predicts outcome in critically ill patients. Crit Care Explor. 2020;2(8):e0171. doi:10.1097/CCE.000000000000171.

47. Joyce PR, O’Dempsey R, Kirby G, Anstey C. A retrospective observational study of sarcopenia and outcomes in critically ill patients. Anaesth Intensive Care. 2020;48(3):229-235. doi:10.1177/031005 7 X20922234.

48. Holmes S. The effects of undernutrition in hospitalised patients. Nurs Stand. 2007;22(12):35-38. doi:10.7748/ns2007.11.22.12.35.c6242.
49. Mogensen KM, Robinson MK, Casey JD, et al. Nutritional status and mortality in the critically ill. Crit Care Med; 2015:12-14. doi:10.1097/CCM.0000000000001306.

50. Allingstrup MJ, Esmailzadeh N, Wilkens Knudsen A, et al. Provision of protein and energy in relation to measured requirements in intensive care patients. Clin Nutr. 2012;31(4):462-468. doi:10.1016/j.clnu.2011.12.006.

51. Elke G, Wang M, Weiler N, Day AG, Heyland DK. Close to recommended caloric and protein intake by enteral nutrition is associated with better clinical outcome of critically ill septic patients: secondary analysis of a large international nutrition database. Crit Care. 2014;18(1):1-8. doi:10.1186/cc13720.

52. Mogensen KM, Horkan CM, Purtle SW, et al. Malnutrition, critical illness survivors, and postdischarge outcomes: a Cohort Study. J Parenter Enter Nutr. 2018;42:557-565. doi:10.1177/0148607117709766.

53. Koekkoek KWAC, VanZanten ARH. Nutrition in the critically ill patient. Curr Opin Anaesthesiol. 2017;30(2):178-185. doi:10.1097/ ACO.0000000000000441.

54. Critical Care Nutrition Canadian Clinical Practice Guidelines 2015Summary of revisions to the recommendations. Crit Care Nutr. 2015;1:1-12.

55. Patel JJ, Lemieux M, McClave SA, Martindale RG, Hurt RT, Heyland DK. Critical care nutrition support best practices: key differences between Canadian and American guidelines. Nutr Clin Pract. 2017;32(5):633-644. doi:10.1177/0884533617722165.

56. McClave SA, Taylor BE, Martindale RG, et al. Guidelines for the provision and assessment of nutrition support therapy in the adult critically ill patient: Society of Critical Care Medicine (SCCM) and American Society for Parenteral and Enteral Nutrition (A.S.P.E.N.). J Parenter Enter Nutr. 2016;40(2):159-211. doi:10.1177/0148607115621863.

57. Hoffer LJ, Bistrian BR. Appropriate protein provision in critical illness: a systematic and narrative review. Am J Clin Nutr. 2012;96 (3):591-600. doi:10.3945/ajen.111.032078.

58. Heyland DK, Weijs PJM, Coss-Bu JA, et al. Protein Delivery in the Intensive Care Unit: optimal or Suboptimal? Nutr Clin Pract. 2017;32(1_suppl):58S-71S. doi:10.1177/0884533617691245.

59. Doig GS, Simpson F, Bellomo R, et al. Intravenous amino acid therapy for kidney function in critically ill patients: a randomized controlled trial. Intensive Care Med. 2015;41(7):1197-1208. doi:10.1007/s00134-015-3827-9.

60. Heyland DK, Stapleton R, Compher C. Should we prescribe more protein to critically ill patients? Nutrients. 2018;10(4):6-13. doi:10.3390/nu10040462.

61. Van Zanten ARH, DeWaele E, Wischmeyer PE. Nutrition therapy and critical illness: practical guidance for the icu, post-icu, and long-term convalescence phases. Crit Care. 2019;23(1):1-10. doi:10.1186/ s13054-019-2657-5.

62. Kawaguchi T, Taniguchi E, Sata M. Effects of oral branched-chain amino acids on hepatic encephalopathy and outcome in patients with liver cirrhosis. Nutr Clin Pract. 2013;28(5):580-588. doi:10.1177/ 0884533613496432.

63. Charlton M. Branched-chain amino acids: metabolism, physiological function, and application branched-chain amino acid enriched supplements as therapy for liver disease. J Nutr. 2006;136(1):295-298. doi:10.1093/jn/136.1.295S

64. Marchesini G, Bianchi G, Merli M, et al. Nutritional supplementation with branched-chain amino acids in advanced cirrhosis: a double-blind, randomized trial. Gastroenterology. 2003;124 (7):1792-1801. doi:10.1016/S0016-5085(03)00323-8.

65. Holecek M. Branched-chain amino acids and ammonia metabolism in liver disease: therapeutic implications. Nutrition. 2013;29(10):11 86-1191. doi:10.1016/j.nut.2013.01.022.

66. Ozgultekın A, Turan G, Durmus Y, Dincer E, Akgun N. Comparison of the efficacy of parenteral glutamine and branched-chain amino acid solutions given as extra supplements in parallel to the enteral nutrition in head trauma. E Spen Eur E J Clin Nutr Metab; 2008:10-15. doi:10.1016/j.eclnm.2008.05.006. 
67. Patel JJ, Miller KR, Rosenthal C, Rosenthal MD. When is it appropriate to use arginine in critical illness? Nutr Clin Pract. 2016;31 (4):438-444. doi:10.1177/0884533616652576.

68. Morris CR, Hamilton-Reeves J, Martindale RG, Sarav M, Ochoa Gautier JB. Acquired amino acid deficiencies: a focus on arginine and glutamine. Nutr Clin Pract. 2017;32(1_suppl):30S-47S. doi:10. 1177/0884533617691250.

69. Ginguay A, DeBandt JP, Cynober L. Indications and contraindications for infusing specific amino acids (leucine, glutamine, arginine, citrulline, and taurine) in critical illness. Curr Opin Clin Nutr Metab Care. 2016;19(2):161-169. doi:10.1097/MCO.0000000000000255.

70. Tadié JM, Cynober L, Peigne V, et al. Arginine administration to critically ill patients with a low nitric oxide fraction in the airways: a pilot study. Intensive Care Med. 2013;39(9):1663-1665. doi:10. 1007/s00134-013-2984-y.

71. Luiking YC, Poeze M, Deutz NE. A randomized-controlled trial of arginine infusion in severe sepsis on microcirculation and metabolism. Clin Nutr. 2020;39(6):1764-1773. doi:10.1016/j.clnu.20 19.08.013.

72. Drover JW, Dhaliwal R, Weitzel L, Wischmeyer PE, Ochoa JB, Heyland DK. Perioperative use of arginine-supplemented diets: a systematic review of the evidence. J Am Coll Surg. 2011;212 (3):385-399.e1. doi:10.1016/j.jamcollsurg.2010.10.016.

73. Wischmeyer PE. Glutamine and heat shock protein expression. Nutrition. 2002;18(3):225-228. doi:10.1016/S0899-9007(01)00796-1.

74. Bollhalder L, Pfeil AM, Tomonaga Y, Schwenkglenks M. A systematic literature review and meta-analysis of randomized clinical trials of parenteral glutamine supplementation. Clin Nutr. 2013;32(2):213-223. doi:10.1016/j.clnu.2012.11.003.

75. Wischmeyer PE, Dhaliwal R, McCall M, Ziegler TR, Heyland DK. Parenteral glutamine supplementation in critical illness: a systematic review. Crit Care. 2014;18(2):1-17. doi:10.1186/cc13836.

76. Heyland D, Muscedere J, Wischmeyer PE, et al. A randomized trial of glutamine and antioxidants in critically Ill patients. $N$ Engl J Med. 2013;368(16):1489-1497. doi:10.1056/NEJMoa1212722.
77. Heyland DK, Elke G, Cook D, et al. Glutamine and antioxidants in the critically ill patient: a post hoc analysis of a large-scale randomized Trial. J Parenter Enter Nutr. 2015;39(4):401-409. doi:10.11 77/0148607114529994.

78. Van Zanten ARH, Sztark F, Kaisers UX, et al. High-protein enteral nutrition enriched with immune-modulating nutrients vs standard high-protein enteral nutrition and nosocomial infections in the ICU: a randomized clinical trial. JAMA. 2014;312(5):514-524. doi:10.10 01/jama.2014.7698.

79. Mottaghi A, Yeganeh MZ, Golzarand M, Jambarsang S, Mirmiran P. Efficacy of glutamine-enriched enteral feeding formulae in critically ill patients: a systematic review and meta-analysis of randomized controlled trials. Asia Pac J Clin Nutr. 2016;25(3):504-512. doi:10.6133/apjen.092015.24.

80. Lin JJ, Chung XJ, Yang CY, Lau HL. A meta-analysis of trials using the intention to treat principle for glutamine supplementation in critically ill patients with burn. Burns. 2013;39(4):565-570. doi:10.1016/j.burns.2012.11.008.

81. Hammarqvist F. Randomised trial of glutamine-enriched enteral nutrition on infectious morbidity in patients with multiple trauma. JPEN J Parenter Enteral Nutr. 1999;23(1):43-44. doi:10.1177/ 014860719902300143

82. Stehle P, Ellger B, Kojic D, et al. Glutamine dipeptide-supplemented parenteral nutrition improves the clinical outcomes of critically ill patients: a systematic evaluation of randomised controlled trials. Clin Nutr ESPEN. 2017;17:75-85. doi:10.1016/j.clnesp.2016.09.007.

83. Wischmeyer PE. The glutamine debate in surgery and critical care. Curr Opin Crit Care. 2019;25(4):322-328. doi:10.1097/MCC.000 0000000000633.

84. Dr. Daren Heyland et al: Systematic Reviews - Critical care nutrition. Available from: https://www.criticalcarenutrition.com/systematicreviews. Accessed April 21, 2021.
Journal of Multidisciplinary Healthcare

\section{Publish your work in this journal}

The Journal of Multidisciplinary Healthcare is an international, peerreviewed open-access journal that aims to represent and publish research in healthcare areas delivered by practitioners of different disciplines. This includes studies and reviews conducted by multidisciplinary teams as well as research which evaluates the results or conduct of such teams or healthcare processes in general. The journal covers a very wide range of areas and welcomes submissions from practitioners at all levels, from all over the world. The manuscript management system is completely online and includes a very quick and fair peer-review system. Visit http://www.dovepress.com/testimonials. php to read real quotes from published authors. 